\title{
Insulin Pumps
}

\author{
John C. Pickup
}

\section{INTRODUCTION}

T THIS YEAR'S ARTICLE ON insulin pumps includes a number of papers on some longrecognized problems that are potentially associated with continuous subcutaneous insulin infusion (CSII) but here are given new investigation and insights: the occurrence of acute complications, infusion set occlusions and site reactions, and skin complications.

Large registry databases are finding increasing use for the cross-sectional study of insulin pump outcomes. For example, we mentioned the use of the Swedish National Diabetes Register in the ATTD 2015 Yearbook, where cardiovascular mortality was compared in $>18,000$ patients on CSII vs multiple insulin injections (MDI) (1). Karges et al. now use a diabetes care and outcomes registry (the Diabetes Prospective Follow-Up Initiative database) involving $>108,000$ patients, with $>14,000$ patients on CSII in centers in Germany, Austria, Luxembourg, and Switzerland to study the relative frequency of diabetic ketoacidosis (DKA) and severe hypoglycemia in young people on CSII or MDI. Additionally, Hoshina et al. use the Danish Adults with Diabetes database of $>20,000$ patients to study DKA rates on CSII and the influence of clinic size on DKA outcomes.

Infusion site tissue reactions such as inflammation have long been known to occur with CSII and are speculated to influence insulin absorption and glycemic control. But the scientific study of events at the infusion site has been very limited. Hauzenberger and colleagues have now begun to study this important issue by developing and testing a swine model in which tissue samples at the infusion site can be examined for histological changes and inflammatory markers. Two other set-related problems that are covered this year are occlusions and the ability of alarms to detect them in an acceptable time (Freckmann et al.) and the frequency, discomfort, and possible predictors and consequences of the various skin complications associated with CSII (Korsgaard Berg et al.).

Two important issues for the use of pumps in everyday practice are whether there is any difference in the glycemic control that is achievable with different types of pump (such as durable vs patch pump), which Leelarathna et al. investigate in a survey of adults in a large pump clinic, and what is the optimal split in a combination bolus for best management of postprandial hyperglycemia after a high-fat/high-protein meal (Lopez et al.)?

Finally, we turn to some newer issues with CSII that have occupied investigators in the last few years: sensor-augmented pump therapy with automatic low-glucose suspend of the basal rate, the value of CSII in type 2 diabetes and new insulins that might further improve control on pumps. We include one of the first long-term randomized controlled trials (RCTs) of threshold vs predictive low-glucose insulin suspend pumps, investigating whether there is a difference in hypoglycemia reduction (Abraham et al.). Mader et al. describe the short-term efficacy of a simpler subcutaneous insulin infusion device for the treatment of type 2 diabetes that might be more cost effective in this group; and Zijlstra et al. investigate the pump compatibility of a new, faster-acting insulin formulation of aspart when used in CSII.

Faculty of Life Sciences and Medicine, King's College London, Guy's Hospital, London, UK 
Key Articles Reviewed for the Article

Association of insulin pump therapy vs insulin injection therapy with severe hypoglycemia, ketoacidosis, and glycemic control among children, adolescents, and young adults with type 1 diabetes

Karges B, Schwandt A, Heidtmann B, Kordonouri O, Binder E, Schierloh U, Boettcher C, Kapellen T, Rosenbauer J, Holl RW

JAMA 2017; 318: 1358-1366

Treatment modality-dependent risk of diabetic ketoacidosis in patients with type 1 diabetes: Danish Adult Diabetes Database Study

Hoshina S, Andersen GS, Jørgensen ME, Ridderstråle M, Vistisen D, Andersen $H U$

Diabetes Technol Ther 2018; 20: 229-234

Systematic in vivo evaluation of the time-dependent inflammatory response to steel and Teflon insulin infusion catheters

Hauzenberger JR, Münzker J, Kotzbeck P, Asslaber M, Bubalo V, Joseph JI, Pieber TR

Scientific Reports 2018; 8: 1132

Occlusion detection time in insulin pumps at two different basal rates

Freckmann $G$, Kamecke $U$, Waldenmaier D, Haug C, Ziegler $R$

J Diabet Sci Technol 2018; 12: 608-613

Skin problems associated with insulin pumps and sensors in adults with type 1 diabetes: a cross-sectional study

Korsgaard Berg A, Nørgaard K, Thyssen JP, Zachariae C, Hommel E, Rytter K, Svensson $J$

Diabet Technol Therapeut 2018; 20: 475-482

Comparison of different insulin pump makes under routine care conditions in adults with type 1 diabetes

Leelarathna L, Roberts SA, Hindle A, Markakis K, Alam T, Chapman A, Morris J, Urwin A, Jinadev $P$, Rutter $M K$

Diabet Med 2017; 34: 1372-1379

Optimizing the combination insulin bolus split for a high-fat, high-protein meal in children and adolescents using insulin pump therapy

Lopez PE, Smart CE, McElduff P, Foskett DC, Price DA, Paterson MA, King BR

Diabet Med 2017; 34: 13801384

Reduction in hypoglycemia with the predictive low-glucose management system: a long-term randomized controlled trial in adolescents with type 1 diabetes

Abraham MB, Nicholas JA, Smith GJ, Fairchild JM, King BR, Ambler GR, Cameron FJ, Davis EA, Jones TW; on behalf of the PLGM Study Group

Diabetes Care 2018; 41: 303-310

Improved glycaemic control and treatment satisfaction with a simple wearable 3-day insulin delivery device among people with type 2 diabetes

Mader JK, Lilly LCL, Aberer F, Poettler T, Johns D, Trautmann M, Warner J, Pieber TR

Diabet Med 2018; 35: 1448-1456

Investigation of pump compatibility of fast-acting insulin aspart in subjects with type 1 diabetes

Zijlstra E, Demissie M, Graungaard T, Heise T, Nosek L, Bode B

J Diabet Sci Technol 2018; 12: 145-151 


\section{ACUTE COMPLICATIONS OF DIABETES DURING CSII}

\section{Association of insulin pump therapy vs insulin injection therapy with severe hypoglycemia, ketoacidosis, and glycemic control among children, adolescents, and young adults with type 1 diabetes}

Karges $B^{1}$, Schwandt $A^{2,3}$, Heidtmann $B^{4}$, Kordonouri $O^{5}$, Binder $E^{6}$, Schierloh $U^{7}$, Boettcher $C^{8}$, Kapellen $T^{9}$, Rosenbauer $J^{3,10}$, Holl $R W^{2,3}$

${ }^{I}$ Division of Endocrinology and Diabetes, Medical Faculty, Rheinisch-Westfälische Technische Hochschule (RWTH) Aachen University, Aachen, Germany; ${ }^{2}$ Institute of Epidemiology and Medical Biometry, Central Institution for Biomedical Engineering (ZIBMT), University of Ulm, Ulm, Germany; ${ }^{3}$ German Center for Diabetes Research (DZD), Neuherberg, Germany; ${ }^{4}$ Children's Hospital Wilhelmstift, Hamburg, Germany; ${ }^{5}$ Diabetes Center for Children and Adolescents, Children's Hospital Auf Der Bult, Hannover, Germany; ${ }^{6}$ Department of Pediatrics, Medical University of Innsbruck, Innsbruck, Austria; ${ }^{7}$ Department of Pediatrics, Centre Hospitalier de Luxembourg, Luxembourg City, Luxembourg; ${ }^{8}$ Division of Paediatric Endocrinology and Diabetology, Center of Child and Adolescent Medicine, Justus Liebig University Giessen, Giessen, Germany; ${ }^{9}$ Hospital for Children and Adolescents, University of Leipzig, Leipzig, Germany; ${ }^{10}$ Institute for Biometrics and Epidemiology, German Diabetes Center, Leibniz Center at the University of Düsseldorf, Düsseldorf, Germany

JAMA 2017; 318: 1358-1366

This manuscript is also discussed in the article on Diabetes Technology and Therapy in the Pediatric Age Group, page S-123.

\section{Background}

The association between insulin pump therapy (CSII) and acute diabetes complications has not been comprehensively studied because it requires large numbers of subjects. The aim of this study, therefore, was to compare the frequency of severe hypoglycemia ( $\mathrm{SH}$ ) and DKA in young adults, adolescents, and children with type 1 diabetes treated with CSII or MDI using a large population database.

\section{Methods}

Information on people with type 1 diabetes less than 20 years of age and treated by either CSII or MDI (not using continuous glucose monitoring [CGM]) between 2011 and 2015 was recorded from a prospective database of diabetes care and outcomes registry in 446 centers in Germany, Austria, Luxembourg, and Switzerland. The primary outcomes were rates of SH and DKA in the most recent treatment year. Propensity matching of age, sex, diabetes duration, body mass index, migration background, and hemoglobin A1c (HbA1c) identified a cohort with similar baseline characteristics.

\section{Results}

Out of $>30,000$ patients, 9814 on CSII (median 3.7 years pump duration) were matched with 9814 on MDI (median
3.6 years use). $\mathrm{SH}$ rates were significantly lower during pump treatment (9.55 vs 13.97 episodes/100 patient-years, $P<0.001$ ), as was the rate of DKA (3.64 vs 4.26 episodes $/ 100$ patient-years, $P=0.04)$. HbA1c was lower on insulin pump therapy ( 8.04 vs $8.22 \%, P<0.001)$, as was insulin dosage (0.84 vs $0.98 \mathrm{U} / \mathrm{kg}, P<0.001)$.

\section{Conclusions}

CSII is associated with better glycemic control than MDI amongst children and young people with type 1 diabetes, and this is associated with a lower frequency of both SH and DKA.

\section{Treatment modality-dependent risk of diabetic ketoacidosis in patients with type 1 diabetes: Danish Adult Diabetes Database Study}

Hoshina $S^{1,2}$, Andersen $G S^{2}$, Jorgensen $M E^{2,3}$, Ridderstråle $M^{2,4}$, Vistisen $D^{2}$, Andersen $H U^{2}$

${ }^{1}$ Department of Diabetes Center, Tokyo Women's Medical University School of Medicine, Tokyo, Japan; ${ }^{2}$ Steno Diabetes Center Copenhagen, Gentofte, Denmark; ${ }^{3}$ National Institute of Public Health, University of Southern Denmark, Odense M, Denmark; ${ }^{4}$ Novo Nordisk A/S, Clinical Pharmacology, Sфborg, Denmark

Diabetes Technol Ther 2018; 20: 229-234

\section{Background}

The aim of this study was to compare the incidence rates of DKA in adults with type 1 diabetes in Denmark, according to treatment by either CSII or MDI.

\section{Methods}

Information from the Danish Adults with Diabetes Database was retrieved on $>20,000$ people with type 1 diabetes $>17$ years of age, with a mean follow-up time of 5.4 years. Rates of DKA in CSII- and MDI-treated people were compared using models that adjusted for age, sex, diabetes duration, and HbA1c. Rates of DKA in clinics with $<250$ people were compared with those with $\geq 250$ people on CSII, roughly equivalent to regional vs university hospital clinics.

\section{Results}

CSII patients had a lower HbA1c (61.9 vs $66.6 \mathrm{mmol} / \mathrm{mol}$ [7.8 vs $8.2 \%$ ], $P<0.0001)$. In general, DKA rates declined with increasing age, diabetes duration, and increasing HbA1c. In CSII patients, DKA was highest in the first year after starting pump therapy: 36 episodes in year 1,15 in year 2 , and 2 in year 3 . The incidence of DKA was similar on MDI and CSII (27.2 vs 33.8/1000 patients), as was the unadjusted rate ratio (1.23 [95\% confidence interval $0.91-1.65])$ or the rate ratio in models adjusted for confounding factors (1.36 [95\% CI 0.97-1.76]). However, DKA rates were higher in CSII vs MDI patients in small clinics (rate ratio 1.86 [95\% CI 1.30-2.65], $P=0.001$, for the adjusted model).

\section{Conclusions}

When CSII is delivered in large clinics with sufficient patient support and education, there is no increase in DKA in insulin pump-treated patients. 


\section{Comment}

The relative occurrence of SH and DKA during CSII and MDI has been somewhat controversial since the earliest days of pump therapy when there were anecdotal case reports of episodes of both complications during CSII, though observational studies of matched groups of pump and injection-treated patients indicated that SH was less frequent and DKA occurred with similar frequency during CSII vs injection treatment (2). Although several other studies over the last 40 years have shown that DKA occurs at about the same rate on CSII vs MDI (3), it is well known that patients are at risk because cessation of insulin delivery in the event of pump malfunction or infusion set kinking, blockage, or disconnection can lead to more rapid insulin deficiency than with depot insulin injections.

Karges et al. confirm previous meta-analysis data comparing CSII and MDI that has shown significantly less SH during CSII, though the $32 \%$ reduction is much less than the $75 \%$ reduction seen with meta-analysis (4). This might be because of the relatively low rate of $\mathrm{SH}$ in the matched cohort ( $<15$ episodes/100 patient-years), consequent on the shorter duration of diabetes in young people and the known lower rate ratio for $\mathrm{SH}$ reduction with low baseline SH rates (4).

The lower rates of DKA with CSII in the Karges et al. study are of interest, and some other recent observational trials have also reported similar findings (5). Possibly, the lower rate of DKA was linked to the relatively high frequency of self-monitoring of glucose in this population (6.6 times/day vs 5.9 times/day in the T1D Exchange patients of similar age) (6). Other factors that might influence rates of acute complications such as diabetes education, motivation, and adherence to treatment were not measured.

Hoshina et al. show that the frequency of DKA on CSII is highest in the first year after starting a pump and then declines markedly, presumably as patient experience with the technology improves. It has been noted before that DKA rates decline as center experience increases (2), and this fact chimes with the finding of Hoshina et al., in that small clinics have a higher rate of DKA with CSII vs MDI, though the overall DKA rate for the two treatments was similar. All this underlines the role of proper patient education in safe pump procedures to avoid DKA, and thereby the need for trained, experienced, and committed health-care professionals to supervise pump therapy.

\section{INFUSION SETS AND CANNULAE}

\section{Systematic in vivo evaluation of the time-dependent inflammatory response to steel and Teflon insulin infusion catheters}

Hauzenberger $J R^{1}$, Münzker $J^{1}$, Kotzbeck $P^{1}$, Asslaber $M^{2}$, Bubalo $V^{3}$, Joseph $\mathrm{JI}^{4}$, Pieber $\mathrm{TR}^{1}$

${ }^{1}$ Department of Internal Medicine, Division of Endocrinology and Diabetology, Medical University of Graz, Graz, Austria; ${ }^{2}$ Institute of Pathology, Medical University of
Graz, Graz, Austria; ${ }^{3}$ Division of Biomedical Research, Medical University of Graz, Graz, Austria; ${ }^{4}$ Department of Anesthesiology, Jefferson Artificial Pancreas Center, Thomas Jefferson University, Philadelphia, PA

Scientific Reports 2018; 8: 1132

\section{Background}

The aim of the study was to compare the subcutaneous inflammatory response to either Teflon or steel cannulae implanted over 8 days.

\section{Methods}

Commercially available Teflon (Medtronic MiniMed Sure T) or Steel (Quick Set) cannulae were implanted in swine $(n=60$ for each type), and at the end of the study period, tissue was examined for histology, including area of inflammation and density of inflammatory cell infiltration, and quantitative polymerase chain reaction performed for inflammatory markers, including the macrophage marker CD68, and cytokines such as IL-6, IL-8, IL-10, TGF beta, and TNF alpha.

\section{Results}

The area and density of inflammation (mononuclear and neutrophil cells and CD68 expression) increased for both cannula materials over the implantation period, with no significant difference between steel and Teflon cannulae, but fibrosis was more evident for steel cannulae.

\section{Conclusions}

Inflammation at the infusion site increases throughout the wear time, but there is little difference between cannula materials.

\section{Occlusion detection time in insulin pumps at two different basal rates}

Freckmann $G^{l}$, Kamecke $U^{l}$, Waldenmaier $D^{l}$, Haug $C^{l}$, Ziegler $R^{2}$

${ }^{1}$ Institut für Diabetes Technologie Forschungs und Entwicklungsgesellschaft $\mathrm{mbH}$ an der Universität Ulm, Ulm, Germany; ${ }^{2}$ Diabetes Clinic for Children and Adolescents, Muenster, Germany

\section{J Diabet Sci Technol 2018; 12: 608-613}

\section{Background}

Occlusions in insulin infusion sets are common, and their detection and the activation of an alarm are important safety features to avoid impaired insulin delivery and metabolic deterioration with CSII. The occlusion detection time (ODT) may vary according to a number of factors such as detection mechanism, cannula length, and infusion rate. This study aimed to measure the ODT for six types of pump used with different infusion sets with Teflon or steel cannulae.

\section{Methods}

With aspart insulin infused at either 1.0 (typical of use in adults) or $0.1 \mathrm{U} / \mathrm{h}$ (typical of use in children), cannulae were occluded with a clamp (Teflon) or rubber cap. The time to alarm was measured for 10 different pump-infusion set combinations. 


\section{Results}

At $1.0 \mathrm{U} / \mathrm{h}$, all pump systems had an ODT less than 5 hours (median range $34 \mathrm{~min}$ to $3 \mathrm{~h} 55 \mathrm{~min}$; longest individual ODT $4 \mathrm{~h} 48 \mathrm{~min}$ ). However, at $0.1 \mathrm{U} / \mathrm{h}$, the median ODT ranged from about $4 \mathrm{~h}$ to more than $40 \mathrm{~h}$ (longest individual ODT $65 \mathrm{~h} 40 \mathrm{~min}$ ). In most of the pump systems used at $0.1 \mathrm{U} / \mathrm{h}$, the ODT was longer than 24 hours.

\section{Conclusions}

Occlusion alarms cannot be relied upon to detect blockage or other restrictions to flow in infusion sets and cannulae, and insulin pump users should perform regular testing to detect hyperglycemia and ketosis related to occlusions.

\section{Comments}

It is widely recognized that insulin infusion sets and cannulae present a weak point in insulin pump therapy, with problems such as restriction of insulin delivery due to kinking and insulin aggregation-induced occlusion; lipohypertrophy, infection, and inflammation at the infusion site; and limitation of the wear time of a single set at a single site to no longer than about 3 days (7). Most of our knowledge of infusion set issues comes from patient questionnaires and is thus retrospective and subjective, and it is surprising that there has been little scientific study of, say, the cellular and biochemical responses at the infusion site, whether this differs between cannula materials, and whether changing responses are directly related to glycemic outcomes with CSII such as blood glucose variability. Hauzenberger et al. are beginning to study these problems by testing an animal model in which the inflammatory response can be quantified and perhaps related to factors such as insulin absorption.

There are several problems in the interpretation of this study, including the fact that insulin was not infused through the sets. This might modify the tissue response if only because insulin is a known anti-inflammatory agent (8). The animals were also nondiabetic, and possibly this was a consideration in interpretation since diabetes is known to suppress immune responses, increasing the risk of infection and delaying wound healing (9). And although the pig is usually considered a good model for subcutaneous insulin absorption, responses may differ from that of humans. The real issue is whether the increasing inflammation relates to any change in insulin absorption and glycemic control. This was not studied here, and in a companion paper elsewhere (10), the authors were unable to correlate the extent of inflammation at the cannula implantation site in pigs with the kinetics of insulin absorption because of small numbers of studies. More work is needed in this area.

In the study of Freckmann et al., the ODT was acceptable at an infusion rate of $1.0 \mathrm{U} / \mathrm{h}$, typical for adults with type 1 diabetes, but the longer ODT found (mostly $>24 \mathrm{~h}$ ) at the lower infusion rate of $0.1 \mathrm{U} / \mathrm{h}$, such as might be used in many children, is potentially concerning. An 8$\mathrm{h}$ overnight interruption of flow in the basal state would probably be unlikely to lead to serious ketosis and hyperglycemia but, with infection and/or stress, insulin deficiency will lead to more rapid ketosis. In any event, it emphasizes the need for regular monitoring, instruction in sick-day rules, and prompt responses to unexplained hyperglycemia in order to avoid metabolic decompensation after infusion set occlusion.

\section{Skin problems associated with insulin pumps and sensors in adults with type 1 diabetes: a cross- sectional study}

Korsgaard Berg $A^{1,2}$, Norgaard $K^{2,3}$, Thyssen $\mathrm{JP}^{4}$, Zachariae $C^{4}$, Hommel $E^{5}$, Rytter $K^{5}$, Svensson $J^{1,2}$

${ }^{I}$ Department of Pediatrics, Copenhagen Diabetes Research Center (CPH-DIRECT), Copenhagen University Hospital, Herlev and Gentofte, Herlev, Denmark; ${ }^{2}$ Faculty of Health Science, University of Copenhagen, Denmark; ${ }^{3}$ Department of Endocrinology, Copenhagen University Hospital, Hvidovre, Denmark; ${ }^{4}$ Department of Dermatology and Allergy, Copenhagen University Hospital, Herlev and Gentofte, Hellerup, Denmark; ${ }^{5}$ Steno Diabetes Center Copenhagen, Gentofte, Denmark

Diabet Technol Therapeut 2018; 20: 475-482

\section{Background}

Both CSII and CGM are associated with dermatological complications that might affect adherence or glycemic control. Little is known about the predictors of these problems. The aim of this study was to describe the skin complications associated with CSII and CGM in adults with type 1 diabetes.

\section{Methods}

Patients on CSII or CGM for at least 4 weeks completed an online questionnaire $(n=118)$ that included demographic details and HbA1c and an assessment of dermatological problems associated with CSII or CGM according to eight pictures, or they gave a text description of the skin problem, as well as completing a five-point discomfort scale. Selfreported history of atopic disease was also recorded.

\section{Results}

Of those who completed the questionnaire, $79.5 \%$ were on CSII and $40.7 \%$ on CGM. Previous skin complications were noted by $79.5 \%$ on CSII and $71.4 \%$ on CGM, and more than onethird had current complications with both technologies. Eczema and old scars were common, followed by dry and wet wounds and red/blue dots. There was no association with $\mathrm{HbA1c}$ or the frequency of infusion set change, but for CSII, history of atopy was related to skin complications in multivariate analysis.

\section{Conclusions}

Skin problems are commonly associated with CSII and CGM and represent a significant challenge to management. Studies are needed to develop preventive and treatment strategies.

\section{Comments}

Skin problems have been noted since the earliest days of CSII, particularly infection and inflammation, and lipohypertrophy at the infusion site (11). Skin abscesses 
were often seen in the early days of CSII, but with improved hygiene and education of patients in best practices for set use and change, the frequency has declined dramatically.

It is interesting that no association with set change was noted here, since there is a common belief that extended use of infusion sets leads to site inflammation and poor control with CSII. Possibly the fact that most of the sets were used for only 3 days (the longest was only 3.8 days) limited the occurrence of site inflammation and other skin problems.

In this study, there were no apparent differences in skin complications between pump, set, and sensor types, but there were few patients who used steel cannulae, so any association with Teflon vs metal cannulae could not be determined. Most of the patients regarded the lesions as causing only small or moderate discomfort, and one must conclude that they were continuing with CSII or CGM despite the skin issues because of the clear advantages of the technologies. However, it must be noted that this study was of "users" and it is possible that a cohort of non-studied patients had discontinued CSII or CGM specifically because of dermatological complications. In a recent evaluation of pump discontinuation in the T1D Exchange registry (12), the most common reason given for stopping CSII was wearability issues, and this included skin reactions, among other issues such as pump discomfort, adhesion problems, and difficulties with sports and activities. However, the discontinuation rate for CSII is low, generally $<5 \%$, so the number of those started on CSII who discontinue because of skin complications is likely to be small.

\section{PUMPS IN PRACTICE}

\section{Comparison of different insulin pump makes under routine care conditions in adults with type 1 dia- betes}

Leelarathna $L^{1,2}$, Roberts $S A^{3}$, Hindle $A^{2}$, Markakis $K^{1}$, Alam $T^{2}$, Chapman $A^{1}$, Morris $J^{1}$, Urwin $A^{1}$, Jinadev $P^{1}$, Rutter $M K^{1,2}$

${ }^{1}$ Manchester Diabetes Centre, Central Manchester University Hospitals NHS Foundation Trust, Manchester Academic Health Science Centre; ${ }^{2}$ Division of Diabetes, Endocrinology and Gastroenterology, University of Manchester; ${ }^{3}$ Centre for Biostatistics, Manchester Academic Health Science Centre, University of Manchester, Manchester, UK

Diabet Med 2017; 34: 1372-1379

\section{Background}

Potentially, there may be differences in the glycemic effectiveness of various makes of insulin pumps because of such factors as differences in accuracy, bolus advisor algorithms, the setting and calculation of correction doses and insulin-on-board, and the susceptibility to pump position (the "siphon effect"). The aim of this study, therefore, was to compare the long-term HbA1c changes associated with dif- ferent pump types used in a cohort of adults with type 1 diabetes under real-life conditions.

\section{Methods}

A retrospective analysis was performed of all adults with type 1 diabetes who were started on CSII from 1999 to 2014 at a single, large pump center in the UK; $\mathrm{n}=508$ had pre- and post-pump HbA1c data.

\section{Results}

The median duration of CSII was 3.7 years. Pump manufacturers were Medtronic 50\%, Omnipod 24\%, Roche 14\%, and Animas $12 \%$, with no difference in starting HbA1c between models. For the whole cohort, median HbA1c improved from 8.7 to $8.2 \%$ ( 71 to $66 \mathrm{mmol} / \mathrm{mol}, P<0.0001)$ in the first 12 months. The change in HbAlc was largest in those with the highest baseline HbA1c, and the benefit was maintained over 10 years. There were no between-pump differences in HbA1c, in unadjusted models or when adjusted for age, sex, diabetes duration, baseline HbA1c, and year of pump start. Equally, there were no differences between patch and traditional pumps.

\section{Conclusions}

Since there were no differences in glycemic effectiveness in this study between pump models made by different manufacturers, including comparing traditional or patch pumps, the choice of pump should not be influenced by the degree of HbA1c lowering that is desired.

\section{Comments}

It is surprising that the long-term glycemic effectiveness of insulin pump therapy using different types of pump has not been studied before. This is particularly so since there are reasons both for and against there being differences in blood glucose outcomes between traditional and patch pumps. For example, on the one hand, some studies have shown poorer accuracy with patch pumps (13), though the methods used are debatable and not always comparable, and on the other hand, smaller patch pumps without the longer infusion set may lead to better adherence to pump procedures and therefore better glycemic control. This study indicates that under conditions typical of an average insulin pump clinic, and over an extended period of time, there are no important differences between pumps from different manufacturers.

However, there are some notable caveats. Firstly, the study examined data from adults undergoing CSII. Any inaccuracies of patch pumps, if they exist, seem most evident at low infusion rates, and these are typically in use in children with diabetes, a group not studied here. Secondly, this study looked at only HbA1c as an outcome and not hypoglycemia; disabling hypoglycemia is a major indication for a trial of CSII. Also, as the authors acknowledge, the number of patients in the cohort using sensor-augmented pump therapy was unknown, though it is likely to be small during the years in question. Finally, the number using some pump models was small, so, for example, there were $76 \%$ on traditional pumps vs only $24 \%$ on patch pumps. 
Optimizing the combination insulin bolus split for a high-fat, high-protein meal in children and adolescents using insulin pump therapy

Lopez PE $E^{1,2,3,4}$, Smart $C E^{1,2,4}$, McElduff $P^{2,3}$, Foskett $D C^{5}$, Price $D A^{6,7,8}$, Paterson $M A^{1,2,3,4}$, King $B R^{1,2,3,4}$

${ }^{1}$ John Hunter Hospital, Newcastle, New South Wales, Australia; ${ }^{2}$ University of Newcastle, Newcastle, NSW, Australia; ${ }^{3}$ Hunter Medical Research Institute, Newcastle, NSW, Australia: ${ }^{4}$ Mothers and Babies Research Centre, Newcastle, NSW, Australia; ${ }^{5}$ Insulin Pump Angels, Gold Coast, Queensland, Australia; ${ }^{6}$ Pacific Private Clinic, Gold Coast, Queensland, Australia; ${ }^{7}$ Bond University, Gold Coast, Queensland, Australia; ${ }^{8}$ Griffith University, Gold Coast, Queensland, Australia

Diabet Med 2017; 34: 1380-1384

\section{Background}

The combination bolus in insulin pumps consists of an immediate plus an extended infusion. It is recommended for high-fat and high-protein meals, but effectiveness is not clear from previous studies. It is a pump feature that is not well used, possibly because the best split has not been established. The aim of this study was to optimize the combination bolus split used for a high-fat/high-protein meal in children and young people with type 1 diabetes.

\section{Methods}

Young people with type 1 diabetes $(n=19)$, mean age 12.9 (range 7-21) years, diabetes duration $>1$ year, who were on CSII for $>6$ months, were randomized to receive, on different days, six-bolus regimens (standard immediate bolus +5 combination boluses) in conjunction with a standardized high-protein/high-fat supper meal. The combination splits were (standard:extended) 70:30; 60:40; 50:50; 40:60; and 30:70. CGM was used to monitor glycemic changes.

\section{Results}

For the first 2 hours after the meal, glucose excursions were controlled best by the standard bolus and 70:30 and 60:40 combinations, but these regimens were associated with late hyperglycemia from 120 to $300 \mathrm{~min}$. Glucose excursions after the meal were best controlled by the 30:70 split.

\section{Conclusions}

A 30:70 combination bolus has value in controlling late hyperglycemia, but with a total insulin dose based on carbohydrate content, neither standard nor any combination bolus adequately controlled postprandial hyperglycemia over a 300-min period.

\section{Comment}

This study does not entirely solve the problem of the type of bolus profile that is best for a high-fat/high-protein meal, since none of the profiles tested were successful at restricting hyperglycemia for the entire period. It might also be significant that the bolus insulin in this study was given at the start of the meal, rather than 15-20 min before, which, at least for a typical (non-high-fat/protein) meal, is the optimal timing to control postprandial glucose rises. Possibly the 30:70 combination would have been more effective when started before the meal (so that the immediate component had more time to be absorbed). In any event, additional immediate insulin dosage or insulinization (via appropriate timing) is needed with the combination profile.

In another recent study comparing high- and low-fat/ protein meals in children on CSII (14), the extended hyperglycemia of the former meal type was greatest in those with longest diabetes duration, largest daily insulin dose, and highest $\mathrm{HbA1c}$, suggestive of a role of insulin resistance in determining the individual response to a high-fat/protein meal. More work is needed in this area.

\section{PREDICTIVE LOW-GLUCOSE INSULIN SUSPEND PUMPS}

Reduction in hypoglycemia with the predictive lowglucose management system: a long-term randomized controlled trial in adolescents with type 1 diabetes

Abraham $M^{1-3}$, Nicholas $J A^{1,2}$, Smith $G^{2}{ }^{2}$, Fairchild $J^{4}{ }^{4}$, King $\mathrm{BR}^{5}$, Ambler $\mathrm{GR}^{6}$, Cameron $\mathrm{FJ}^{7}$, Davis $\mathrm{EA}^{1-3}$, Jones TW ${ }^{1-3}$; on behalf of the PLGM Study Group

${ }^{1}$ Children's Diabetes Centre, Telethon Kids Institute, The University of Western Australia, Perth, Australia; ${ }^{2}$ Department of Endocrinology and Diabetes, Princess Margaret Hospital for Children, Perth, Australia; ${ }^{3}$ Division of Paediatrics, Medical School, The University of Western Australia, Perth, Australia; ${ }^{4}$ Department of Endocrinology and Diabetes, Women's and Children's Hospital, Adelaide, Australia; ${ }^{5}$ Department of Endocrinology and Diabetes, John Hunter Children's Hospital, Newcastle, Australia; ${ }^{6}$ Institute of Endocrinology and Diabetes, The Children's Hospital at Westmead and Clinical School, The University of Sydney, Sydney, Australia; ${ }^{7}$ Department of Endocrinology and Diabetes, The Royal Children's Hospital, Melbourne, Australia

Diabetes Care 2018; 41: 303-310

This manuscript is also discussed in the article on Diabetes Technology and Therapy in the Pediatric Age Group, page S-123.

\section{Background}

Previous trials comparing glycemic outcomes with sensoraugmented insulin pump therapy (SAP) with threshold lowglucose insulin suspend vs predictive low-glucose suspend (PLGS) pumps have been short term. The aim of this study was to compare the long-term effectiveness of these types of SAP therapy in young people with type 1 diabetes.

\section{Methods}

This was a multicenter RCT in which patients aged 8-20 years were allocated to either threshold SAP or PLGS pump therapy (Medtronic 640G) over 6 months. The primary outcome was time spent with sensor glucose $<3.5 \mathrm{mmol} / \mathrm{L}$ $(63 \mathrm{mg} / \mathrm{dL})$, but with questionnaires for quality of life and fear of hypoglycemia assessment. 


\section{Results}

After dropouts and exclusions, 154 patients were analyzed (74 on SAP and 80 on PLGS pumps). All had $>80 \%$ sensor use. Time $<3.5 \mathrm{mmol} / \mathrm{L}$ was reduced from baseline in both arms (3.0\% to $2.6 \%$ for SAP; $2.4 \%$ to $1.4 \%$ for PLGS), but the reduction was lower for PLGS (difference $-0.9 \%, P<0.0001$ ). HbA1c was not significantly different at 6 months (7.6 vs $7.8 \%$, SAP vs PLGS, $P=0.35)$. The reduction in hypoglycemia with PLGS pumps was seen during both day and night. There were no episodes of severe hypoglycemia in either group. There was no effect of treatment on hypoglycemia awareness, quality of life, or the fear of hypoglycemia score.

\section{Conclusions}

PLGS pumps reduce hypoglycemia in young people with type 1 diabetes to a greater extent than SAP with threshold suspend, without deterioration in overall control.

\section{Comments}

PLGS pumps have been in clinical practice for some time now, but robust evidence from RCTs for their long-term effectiveness vs threshold-based low-glucose suspend has been slow to accumulate. This randomized but unblinded study is important because it examines the effect on CGM-measured hypoglycemia over 6 months. The results confirm that PLGS is more effective than threshold SAP pumps at reducing time spent in the hypoglycemic range, but one should note that no severe hypoglycemia occurred in either group, and this was not a cohort with disabling hypoglycemia-only $17 \%$ of the participants had hypoglycemia unawareness at baseline. The failure to show any change in quality of life or fear of hypoglycemia may be because hypoglycemia was reduced but not completely abolished or because significant improvement of these psychosocial indices occurs predominantly with reduction in severe disabling hypoglycemia.

\section{CSII IN TYPE 2 DIABETES}

\section{Improved glycaemic control and treatment satisfaction with a simple wearable 3-day insulin delivery device among people with type 2 diabetes}

Mader $J K^{l}$, Lilly $L C L^{2}$, Aberer $F^{l}$, Poettler $T^{l}$, Johns $D^{3}$, Trautmann $M^{4}$, Warner $J^{5}$, Pieber $T R^{1}$

${ }^{1}$ Medical University of Graz, Graz, Austria; ${ }^{2}$ Lilly Consulting, Concord, MA; ${ }^{3} B 2 S$ Life Sciences, Franklin, IN; ${ }^{4}$ Diabetes Research, Hamburg, Germany; ${ }^{5}$ CeQur Corporation, Marlborough, MA

Diabet Med 2018; 35: 1448-1456

\section{Background}

CSII is effective in type 2 diabetes, but insulin pumps intended for type 1 diabetes are expensive and complicated, with features that may not be required for type 2 diabetes. Most patients with type 2 diabetes can be managed with a single basal rate on CSII and bolus calculators may offer no additional benefit. The aim of this study was to test a simple 3-day insulin infusion device (PAQ, CeQur Corp) in type 2 diabetes.

\section{Methods}

Adults with type 2 diabetes (mean age 63 years; mean baseline $\mathrm{HbA} 1 \mathrm{c} 8.6 \%$ [70 $\mathrm{mmol} / \mathrm{mol}]$ ) on at least two insulin injections/day were switched to the PAQ device for 12 weeks, after a transition period for deciding the most suitable basal rate option. The PAQ has five set basal rates (0.83-2.08 units/day) and on-demand bolus insulin delivery in 2-unit increments. The primary outcome was change in $\mathrm{HbA1c}$, with additional seven-point self-monitored blood glucose (SMBG) profiles and questionnaire assessments of patientreported outcomes, including treatment satisfaction.

\section{Results}

Most patients (75\%) continued on the same basal rate first selected; $n=24$ completed the study. At 12 weeks, HbA1c was significantly lower than at baseline: change $-1.5 \%$ $(-16 \mathrm{mmol} / \mathrm{mol}, P<0.0001)$. All time points of the SMBG profile were also lower at the end of the study, $P \leq 0.03$. The mean insulin dose increased by 12.1 units/day $(P=0.006)$, with no weight change or severe hypoglycemia. The treatment satisfaction score was improved at 12 weeks.

\section{Conclusions}

Adults with insulin injection-treated type 2 diabetes were safely transitioned to a simple infusion device, with improved glycemic control and treatment satisfaction at the end of the treatment period.

\section{Comment}

There is increasing interest in clinical practice for the use of CSII in type 2 diabetes when HbAlc has failed to reach target levels with best insulin injection regimens. The evidence base for this strategy relies largely on trials such as the recent OpT2mise study (15), which use traditional pumps intended for type 1 diabetes, and these are not likely to be cost-effective or affordable for the large numbers of type 2 patients who might be candidates for a trial of CSII. There is therefore a need for simpler, potentially cheaper, infusion devices that take advantage of the simpler infusion requirements that work for most type 2 patients - a single, fixed basal rate and bolus delivery system without a bolus calculator. This pilot observational study tests an example of such a new-generation pump that is effective at reducing HbAlc in poorly controlled type 2 diabetes. But RCTs are now needed with larger numbers of patients studied over longer periods to fully evaluate the clinical effectiveness of this type of device.

\section{NEW INSULINS FOR CSII}

\section{Investigation of pump compatibility of fast-acting insulin aspart in subjects with type 1 diabetes}

Zijlstra $E^{l}$, Demissie $M^{2}$, Graungaard $T^{2}$, Heise $T^{l}$, Nosek $L^{1}$, Bode $B^{3}$

${ }^{I}$ Profil, Neuss, Germany; ${ }^{2}$ Novo Nordisk A/S, Sфborg, Denmark; ${ }^{3}$ Atlanta Diabetes Associates, Atlanta, GA

J Diabet Sci Technol 2018; 12: 145-151 


\section{Background}

Fast-acting insulin aspart (Fiasp) is aspart insulin formulated with the excipients niacinamide and L-arginine; it has an earlier onset and earlier glucose lowering effect than aspart when injected subcutaneously and may be advantageous for use in insulin pump therapy. The aim of this study was to investigate the compatibility, safety, and short-term efficacy of Fiasp when used in CSII.

\section{Methods}

This was a double-blind RCT in which adults with type 1 diabetes using CSII for at least 6 months prior to the trial were recruited. After a 2-week run-in to optimize pump treatment, patients were randomized $2: 1$ to Fiasp $(n=25)$ or aspart $(n=12)$ for 6 weeks. Subjects were instructed to change the infusion set every 72 hours unless occlusion was suspected; there was unexplained hyperglycemia, leakage, or a site reaction; or there was another technical problem. Laboratory macro- and microscopic examination of prematurely changed sets and reservoirs was performed to confirm occlusion.

\section{Results}

There were premature set changes in $44 \%$ of Fiasp and $16.7 \%$ of aspart-allocated patients. No microscopically confirmed occlusions occurred in either treatment arm. Macroand microscopic examination indicated no color change in the insulin solution, or particle, crystal, or plug that was indicative of occlusion. Most changes were due to technical problems, including leakage, kinking, empty reservoir, and dislodged cannulae. There was no significant difference in HbAlc between the treatments but a numerically lower $\mathrm{HbA} 1 \mathrm{c}$ level in the Fiasp arm (HbA1c difference $-0.14 \%$ [95\% CI -0.40 to $0.11]$ at 16 weeks). There were no safety issues.

\section{Conclusions}

Since no occlusions were detected, there appears to be similar compatibility for Fiasp and aspart when used for insulin infusion pump therapy.

\section{Comment}

Faster-acting insulins like Fiasp should help to limit postprandial glucose increments during CSII and should thus further improve the glycemic control that can be achieved with pump therapy. There are some cautionary notes to be expressed with this study, however. Subjects were asked to - and on average actually did — change the infusion sets after no more than 3 days' use. This is the standard and, most practitioners would agree, the correct clinical advice. But there is evidence that the frequency of set occlusions and/or insulin precipitation is higher when set use extends beyond this duration $(16,17)$, particularly with lispro and glulisine insulins. Since many patients in practice use the set for longer than the recommended 3 days, it will be important to test compatibility of Fiasp under these circumstances. In a Swedish survey of CSII, for example, Teflon cannulae were used for 2-10 days (mean 4.8 days) and steel cannulae for 1.5-7.5 (mean 3.8 days) (18).

Although it is reassuring that no macro- or microscopic evidence of occlusions was seen, there was a greater frequency of unexplained hyperglycemia $(40 \%$ vs $25 \%$ ) and set change (44\% vs $16.7 \%$ ) in the Fiasp vs aspart groups. Unexplained hyperglycemia that does not trigger an alarm (a "silent occlusion") has several possible causes but is often attributed to small impairments of insulin flow because of micro-occlusions due to insulin aggregation or tissue reactions/blockages at the infusion site. The trial of Zjilstra et al. had too few subjects studied over too short of a period to fully assess the relative frequency of unexplained hyperglycemia and, again, such episodes may be more likely after 3 days of set use. This needs further study. Equally, the 16-week study period was too short to assess changes in HbAlc (or severe hypoglycemia), so any impact of, say, a small increase in the frequency of unexplained hyperglycemia could not be measured with any confidence.

\section{Author Disclosure Statement}

J.C.P. has received speaker and/or consultancy fees from CeQur, Medtronic, Novo Nordisk, and Roche, manufacturers of insulin pumps or insulin formulations.

\section{References}

1. Steineck I, Cederholm J, Eliasson B, Rawshani A, EegOlofsson K, Svensson A-M, et al. Insulin pump therapy, multiple daily injections, and cardiovascular mortality in 18168 people with type 1 diabetes: observational study. BMJ 2015; 350: h3234.

2. Bending JJ, Pickup JC, Keen H. Frequency of diabetic ketoacidosis and hypoglycemic coma during treatment with continuous subcutaneous insulin infusion. Am J Med 1985; 79: 685-691.

3. Linkeschova R, Raoul M, Bott U, Berger M, Spraul M. Less severe hypoglycaemia, better metabolic control, and improved quality of life in type 1 diabetes mellitus with continuous subcutaneous insulin infusion (CSII) therapy; an observational study of 100 consecutive patients followed for a mean of 2 years. Diabet Med 2002; 19: 746-51.

4. Pickup JC, Sutton AJ. Severe hypoglycaemia and glycaemic control in type 1 diabetes: meta-analysis of multiple daily insulin injections versus continuous subcutaneous insulin infusion. Diabetic Med 2008; 25: 765-774.

5. Bruttomesso D, Costa S, Baritussio A. Continuous subcutaneous insulin infusion (CSII) 30 years later: still the best option for insulin therapy. Diabet Metab Res Rev 2009; 25: 99-111.

6. Miller KM, Foster NC, Beck RW, Bergenstal RM, DuBose SN, DiMeglio LA, et al.; for the T1D Exchange Clinic Network. Current state of type 1 diabetes treatment in the US: updated data from the T1D Exchange Clinic Registry. Diabetes Care 2015; 38: 971-978.

7. Heinemann L. Insulin infusion sets: a critical reappraisal. Diabet Technol Therapeut 2016; 18: 337-333.

8. Dandona P, Chaudhuri A, Mohanty P, Ghanim H. Antiinflammatory effects of insulin. Curr Opin Clin Nutr Metab Care 2007; 10: 511-517.

9. Joshi N, Caputo GM, Weitekamp MR, Karchmer AW. Infections in patients with diabetes mellitus. $N$ Engl J Med 1999; 341: 1906-1912.

10. Hauzenberger JR, Hipszer BR, Loeum C, McCue PA, DeStefano M, Torjman MC, et al. Detailed analysis of 
insulin absorption variability and the tissue response to continuous subcutaneous insulin infusion catheter implantation in swine. Diabetes Technol Ther 2017; 19: 641-650.

11. Levandoski LA, White NH, Santiago JV. Localized skin reactions to insulin: insulin lipodystrophies and skin reactions to pumped subcutaneous insulin therapy. Diabetes Care 1982; 5 (Suppl 1): 6-10.

12. Wong JC, Boyle C, DiMeglio LA, Mastrandrea LD, Abel KL, Cengiz E, et al; T1D Exchange Clinic Network. Evaluation of pump discontinuation and associated factors in the T1D Exchange Clinic Registry. J Diabet Sci Technol 2017; 11: 224-232.

13. Borot S, Franc S, Cristante J, Penfornis A, Benhamou PY, Guerci B, et al.; Diabeloop Study Group. Accuracy of a new patch pump based on a microelectromechanical system (MEMS) compared to other commercially available insulin pumps: results of the first in vitro and in vivo studies. J Diabet Sci Technol 2014; 8: 1133-1141.

14. van der Hoogt M, van Dyk JC, Dolman RC, Pieters M. Protein and fat meal content increase insulin requirement in children with type 1 diabetes-role of duration of diabetes. J Clin Translat Endocrinol 2017; 10: 15-21.

15. Reznik Y, Cohen O, Aronson R, Conget I, Runzis S, Castaneda J, Lee SW; for the OpT2mise Study Group. Insulin pump treatment compared with multiple daily injections for treatment of type 2 diabetes (OpT2mise): a randomised open-label controlled trial. Lancet 2014; 384: 1265-1272.

16. Kerr D, Morton J, Whately-Smith C, Everett J, Begley JP. Laboratory-based non-clinical comparison of occlusion rates using three rapid-acting insulin analogs in continuous subcutaneous insulin infusion catheters using low flow rates. J Diabet Sci Technol 2008; 2: 450-455.

17. Pickup JC, Yemane N, Brackenridge A, Pender S. Nonmetabolic complications of continuous subcutaneous insulin infusion: a patient survey. Diabet Technol Therapeut 2014; 16: 145-149.

18. Johansson UB, Adamson U, Lins PE, Wredling R. Patient management of long-term continuous subcutaneous insulin infusion. $J$ Adv Nurs 2005; 51: 112-118. 